\title{
An optimization model for management of empty containers in distribution network of a logistics company under uncertainty
}

\author{
Ahmad Hosseini ${ }^{1} \cdot$ Tobias Sahlin ${ }^{2}$ \\ Received: 10 April 2018/Accepted: 6 August 2018/Published online: 16 August 2018 \\ (C) The Author(s) 2018
}

\begin{abstract}
In transportation via containers, unbalanced movement of loaded containers forces shipping companies to reposition empty containers. This study addresses the problem of empty container repositioning (ECR) in the distribution network of a European logistics company, where some restrictions impose decision making in an uncertain environment. The problem involves dispatching empty containers of multiple types and various conditions (dirty and clean) to meet the on-time delivery requirements and repositioning the other containers to terminals, depots, and cleaning stations. A multi-period optimization model is developed to help make tactical decisions under uncertainty and data shortage for flow management of empty containers over a predetermined planning horizon. Employing the operational law of uncertainty programming, a new auxiliary chance-constrained programming is established for the ECR problem, and we prove the existence of an equivalence relation between the ECR plans in the uncertain network and those in an auxiliary deterministic network. Exploiting this new problem, we give the uncertainty distribution of the overall optimal ECR operational cost. The computational experiments show that the model generates good-quality repositioning plans and demonstrate that cost and modality improvement can be achieved in the network.
\end{abstract}

Keywords Operations research $\cdot$ Uncertain programming $\cdot$ Logistics $\cdot$ Intermodal transport $\cdot$ Repositioning

\section{Introduction}

Lured by the promise of bigger sales, companies are seeking to raise the volume of international trade. Consequently, the amount of bulk products carried in containers and transported overseas exploded as this type of transportation is environment-friendly, secure, flexible, reliable, and less prone to spillage (Crainic et al. 1993; Erera et al. 2005; Ünlüyurt and Aydın 2012; Zhang et al. 2017). Therefore, it comes as no surprise that container-based transportation offers a high degree of productivity and provides undeniable advantages in terms of losses and damages. However, minimizing the logistics and distribution costs arising from the container flow management

Ahmad Hosseini

ahmadh@cs.umu.se

1 Department of Computing Science, Umeå University, 90187 Umeå, Sweden

2 Department of Mathematics and Mathematical Statistics, Umeå University, 90187 Umeå, Sweden across different locations has emerged as a major problem that companies and affiliated third-party logistics firms face in everyday routine (Rashidi and Tsang 2015; Bhattacharya et al. 2014).

A chief challenge that the logistics companies face arises from the imbalance of product supply and demand, and thus an imbalance in the container flow across different regions. As a result, empty containers accumulate at demand centers, which must be efficiently repositioned to ensure the continuity of shipping activities. According to Rodrigue and Notteboom (2015) and Wang and Tanaka (2016), movement of empty containers accounts for circa $30 \%$ of movement of all containers, and about $20 \%$ of global port handling. Therefore, the empty container repositioning (ECR) problem has received a great attention from both industries and academics in recent years, and the need to avoid ad hoc decision-making processes has become vital in container management (SteadieSeifi et al. 2014; Lee and Meng 2014; Song and Dong 2015).

As a class of multi-period distribution planning problems (Ahmad Hosseini et al. 2017; Gen and Syarif 2005; 
Hosseini 2013; Hosseini et al. 2014), this work focuses on the ECR problem in a dynamic environment that occurs in the context of intermodal distributions and transportation operations. This paper is motivated by the analysis of the operational context of a European Logistic Service Provider company (denoted by ELSP throughout the paper) that transports bulk products (chemical, oil, gas, petroleum, foodstuff, etc.) loaded in containers. The ELSP company is an international third-party logistics (3PL) that executes transportation orders via road, rail, short sea, and deep sea, which are supported by strategically located terminals.

This study reveals some characteristics that are rarely described in previous papers, i.e., Liu's uncertainty. Generally, precise information is usually not available on time, which may lead to adverse operational planning reflected in a high degree of variability in system parameters. This may lead to costly transportation and ECR operations which result in lower profit margins. More precisely, some parameters cannot be predetermined prior to planning and indeterminacy should therefore be taken into account by the decision maker. Hence, an uncertain network is a more realistic representation of an actual ECR distribution network.

Although valuable insights have been obtained from the previous studies, the current practice of ECR does not properly account for uncertainty. In other words, there is a lack of suitable optimization methods and models that can simultaneously integrate uncertain factors. Therefore, it is crucial to adopt proper policies in the uncertain environment of ECR problems. To respond to such a need for the analysis of ECR in dynamic uncertain environment, we illustrate a modeling process to take the uncertain nature of ECR parameters into account using the operational law of uncertainty programming. To this aim, we develop an uncertain ECR model that can accommodate uncertainty to ensure an efficient repositioning policy at minimal operational cost, while meeting the time-dependent demand, supply, and capacity requirements.

We address the repositioning of empty containers in a 3PL intermodal distribution network with different types of ports, depots, and terminals discrete-time settings using Liu's (2007) uncertainty. By this approach, a new chanceconstrained programming is established for the ECR problem, which combines assumptions, estimations, knowledge, and experience of a group of domain experts. Associated with any non-deterministic parameter, we introduce an uncertain variable, which is neither fuzzy nor stochastic. We then employ the uncertainty operational law to originally model, solve, and analyze the uncertain ECR problem in the framework of uncertainty programming. Marginally, we introduce the new problem of $(\alpha, \beta, \gamma)$-ECR. We show that there exists an equivalence relation between the uncertain ECR problem and the $(\alpha, \beta, \gamma)$-ECR problem. By using this relation, we solve the original non-deterministic problem and obtain the uncertainty distribution of the optimal distribution cost.

\section{Literature review}

Last decades have witnessed an increased interest in the literature to solve various logistics problems, including ECR, considering different variations of uncertainty accounting for different settings and solution philosophies (Cheung and Chen 1998; Lam et al. 2007; Long et al. 2015; Hosseini 2015; Chiadamrong and Piyathanavong 2017; Nourifar et al. 2018; Hamidi et al. 2017; Tofighian et al. 2018; Hafezalkotob and Zamani 2018; Shishebori and Babadi 2018).

In management of containers, companies have to deal with different uncertain factors, such as the real transportation time between two ports/depots, the future demand and supply, the transit time for returning empty containers from customers, and the available transportation capacity in, e.g., vessels (Crainic et al. 1993; Olivo et al. 2005; Erera et al. 2009; Epstein et al. 2012; Lai 2013; Yi et al. 2016; Finke 2017). As a result, investigations into efficient ECR strategies have drawn the attention of many researchers. There is abundant literature on modeling and optimizing container repositioning. While there is not the space to provide comprehensive mathematical specifications of all methods, an attempt is made to undertake a selective review of those prior studies that have tackled problems somewhat similar in flavor to the problem we deal with in this paper. We also refer to Braekers et al. (2011), Song and Dong (2015), Song and Carter (2009) and Song and Zhang (2010) to get more information regarding ECR problem and different strategies for container repositioning.

According to Dejax and Crainic (1987), although the management of empty container has received much attention since the sixties, little consideration has been, however, dedicated to the development of specific models in the container transportation issue. Aiming at specifying the ratio of empty containers and laden containers to achieve empty container equilibrium, Poo and Yip (2017) study the ECR problem and examine the problem with container inventory management under dynamic condition. Finke (2017) investigates the repositioning problem with nonlogistic theories in order to elucidate problems between different actors in the supply chain of ECR. Ji et al. (2016) study an ECR problem in short sea liner service and develop a dynamic optimization model of ECR for each stage in short sea liner service minimizing the overall repositioning cost during a decision-making horizon. Florez (1986) develops a profit optimization model for the 
ECR and investigates the sensitivity of his proposed model to the length of the planning horizon. Focusing on the business perspective of shipping industry, Shen and Khoong (1995) propose a single-commodity network model under a rolling horizon fashion to minimize the total distribution cost of empty containers. Cheung and Chen (1998) compare a two-stage stochastic model with a twostage deterministic model for the dynamic ECR problem. In a top-to-bottom perspective, Chen (1999) discusses factors causing unproductive moves from operational to strategic levels. Newman and Yano (2000) develop a heuristic approach based on the decomposition procedure to address the day-of-week scheduling of containers. Choong et al. (2002) present an interesting ECR computational analysis. They study the effect of planning horizon length on empty container management for intermodal transportation networks. Olivo et al. (2005) develop an integer program for the ECR between depots and ports through an inland transportation network and solve the model by a linearization technique. Bin and Zhongchen (2007) also consider a multimodal distribution network consisting of ports and inland terminals. Lam et al. (2007) develop a dynamic stochastic model for a two-port twovoyages relocation of empty containers to solve the ECR problems. A general model related to the scheduling of container storage and retrieval is presented in Vis and Roodbergen (2009). The authors present an integer program in a static environment. Shintani et al. (2010) model the ECR problem as an integer program to optimize the repositioning in the hinterland. The authors show the possibility of operational cost reduction through the use of foldable containers instead of standard containers. Long et al. (2012) formulate a two-stage stochastic programming model with random demand, ship weight capacity, and ship space capacity in order to incorporate uncertainty in the ECR problem and minimize the expected operational cost for container repositioning. Later on, Zhang et al. (2014) analyze the multi-period ECR problem with stochastic demand and lost sales aiming to establish an effective ECR policy minimizing the total operating cost. They develop a polynomial-time algorithm to find an approximate repositioning policy for multiple ports. Afterward, Long et al. (2015) computationally examine the impact of several noni.i.d sampling methods for the stochastic ECR problem. By moving forward from imbalance-based locations to shipment network-driven-based container repositioning, Wong et al. (2015) present a yield-based container repositioning framework optimizing the container repositioning from surplus to deficit locations. An extension of the container management problem is to integrate the assignment of loaded containers. It is therefore natural to try to integrate two types of movements, empty and loaded, into the same allocation model. Examples of such models can be found in
Dejax and Crainic (1987), Crainic et al. (1993), Erera et al. (2005), Land et al. (2008) and Brouer et al. (2011).

From another viewpoint, this paper also contributes to the growing body of knowledge regarding the Liu's uncertain programming, by illustrating a modeling process to take the uncertain nature of ECR into account. During the last few years, there has been a vast interest in developing strategies to solve problems in different fields with various uncertain phenomena. Examples of such works can include uncertain multi-item supply chain network (Hosseini 2015), uncertain traffic network (Hosseini and Wadbro 2016), uncertain shortest path (Liu 2010b; Gao 2011), uncertain inference control (Gao 2012), uncertain networks (Liu 2010, 2007), uncertain graph and connectivity (Gao and Gao 2013), uncertain traveling salesman problem (Wang et al. 2013), uncertain multi-product newsboy problem (Ding and Gao 2014), uncertain multi-commodity flow problem (Ding 2017), uncertain maximum flow problem (Ding 2015), uncertain multi-objective programming (Wang et al. 2015), uncertain supplier selection problem (Memon et al. 2015), logistics system under supply and demand uncertainty (Moghaddam 2015), multiregion supply chain under demand uncertainty (Langroodi and Amiri 2016), uncertain railway transportation planning (Gao et al. 2016), uncertain regression analysis (Yao and Liu 2017), and uncertain random assignment problem (Ding and Zeng 2018; Zhang and Peng 2013).

\section{Uncertain ECR model and description}

This work focuses on designing an integrated model for the ELSP company's intermodal distribution network. In order to provide a high service level and gain desired margins concurrently, the empty container management team at the ELSP company seeks to correct imbalances in a cost-efficient course of action while ensuring the on-time delivery requirements. The model aims at facilitating the decision making for the empty container management at tactical level and helps set a framework for operational decisions. Although empty moves do not generate profit; however, due to imbalances in loaded flows, the management of empty containers becomes crucial. Therefore, minimizing such costly moves may considerably reduce the logistics cost. We describe the main decisions and elements characterizing the ECR that may come in different types (five different container dimensions) and container conditions ('dirty' and 'orderly'). Decisions are mainly concerned with

1. where and when empty moves start and finish,

2. where and when containers are cleaned, 
3. the type or dimension (cbm) of empty containers to be sent,

4. the condition of empty containers (dirty or clean) to be delivered,

5. the quantity of empty containers on each link in the network.

In representing the intermodal distribution system of the ELSP company, a mathematical network $D N=(L, A)$ is established. The network consists of several locations (nodes) with different functionalities: depots, cleaning station, railway terminals, port terminals, rail ship terminals, supply customers (unloading sites), demand customers (loading sites), and various transportation links between locations. In our setting, $L$ represent all locations in the distribution network, and $A \subseteq L \times L$ represents all available links between locations for transportation. All such locations are indexed by $l \in L$, and a transportation link between location $l \in L$ and $l^{\prime} \in L$ is denoted by $\left(l, l^{\prime}\right) \in A$. Figure 1 shows all possible/allowed shipments between locations and all available transportation modes between the locations.

Cleaning processes are necessary since demand customers require cleaned/orderly containers. This is of great importance to ensure the safety of the shipment and quality of the delivered products. Hence, it is assumed that a dirty empty container is always sent to a cleaning station for cleaning before reloading at demand customer sites. Both requirements container condition (dirty, orderly) and the container type (size or volume) are considered in the model. In Table 1, containers are classified into five different classes based on their dimensions.
Table 1 Tank container classification, specified by its dimensions

\begin{tabular}{llllll}
\hline Classes & A & B & C & D & E \\
\hline Dimensions (cbm) & $\leq 22$ & {$[22-24]$} & {$[24-27]$} & {$[27-32]$} & $\geq 32$ \\
\hline
\end{tabular}

Some primary and secondary assumptions are made during the modeling. In this project, we have had good historical data and ample seasonal (as well as daily, weekly, and monthly) frequencies to approximate demands. Therefore, the expected demand and supply of empty containers are assumed to be known during the whole planning horizon. The planning horizon is predetermined. All demands of all types of containers must be met by the same type of containers, i.e., substitutions between container types are not included. Container demand cannot be postponed. The model does not consider returning-leased containers to the lessor. It is assumed that a lease term does not expire in the planning horizon. When demand cannot be met (yielding a shortage in the system), containers can be provided by other partners or from external sources (emergency shipments), but at a high cost.

It is important to distinguish between the locations presented in Fig. 1. Depots are mainly utilized for storage, whereas cleaning stations can be employed for both storage and cleaning processes. A few depots and cleaning stations are controlled by the ELSP company, which are referred to as internal locations. The storage costs at these locations are relatively lower compared to external depots and cleaning stations. Railway, port and rail ship terminals provide the options for intermodal transportation. Railway
Fig. 1 Problem overview and the graph of the distribution network

Depots
Cleaning stations
Railway terminals
Port terminals
Rail ship terminals
Demand customers
Supply customers
Road
Rail
Sea
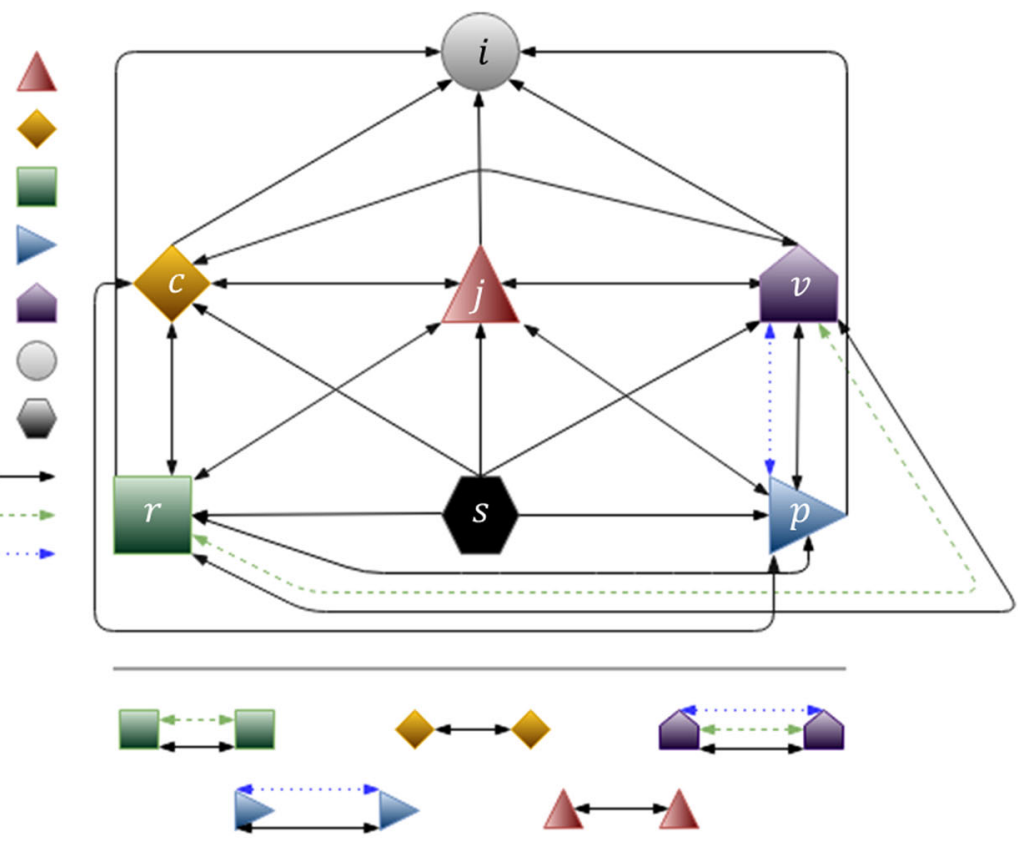
and port terminals are self-descriptive. As indicated in Fig. 1, rail ship terminals allow for both trains and ferries to arrive and depart from. Supply customers provide empty containers that have become available after unloading of the products, while demand customers requires empty containers to be delivered at their site for loading. Note that a customer can be both a demand and a supply customer.

The total supply of empty containers is made up of the stocks stored at each location, the amount in transit, and the number of containers available for pickup at supply customer sites. It is possible to distribute empty containers from supply sites to all locations except demand sites (Fig. 1). Namely, a typical supplier $s$ may be linked to depot $j$, cleaning station $c$, railway terminal $r$, port terminal $p$ and rail ship terminal $v$. Assumptions necessary to postulate are listed below, all of which are standard in majority of container management models.

1. Empty containers are not allowed to be stored at either the supplier sites or demand sites. Hence, after unloading, containers are hauled away immediately to other locations.

2. Transportation capacities between locations, transportation costs over links, and storage costs in locations are assumed to be independent of the type and the condition of the container.

3. Transportation from a location to itself is not allowed, i.e., the distribution network is loop-free.

4. A container is assumed to be dirty after unloading at a supplier site.

5. Arrivals and departures take place in the beginning of time periods.

6. The cleaning times in all cleaning stations are assumed to be same.

7. All shipment modes are assumed to have a limited capacity.

8. The storage times are assumed to be identical.

9. A cleaning process cannot be interrupted.

The model takes several aspects of the problem into account: uncertainty, multiple traveling modes, multiple containers, multiple ports and terminals, and time-varying storage and transportation mode capacities. To facilitate the understanding of the modeling process, we first precisely describe system dynamics, indices, parameters, and decision variables. The decision variables denote the empty container flows between the locations in the underlying network $D N=(L, A)$, stock-out flows (or shortages), and inventories. The temporal horizon, with respect to which the planning horizon is referred, is divided into several periods. Periods can represent hours, days, or weeks depending on the company's needs. Moreover, decisions refer to periods in which they are taken and may have effects in other periods. Hence, there are three main types of decision variables that define where, when, and how the flows of empty container are used.

\section{Sets and Indices}

$T \quad$ Predefined integral planning horizon

$N$ Set of time periods; elements indexed by $t=1,2, \ldots, T-1$

$I \quad$ Set of demand customers; elements indexed by $i=1,2, \ldots,|I|$

$S \quad$ Set of supply centers; elements indexed by $s=1,2, \ldots,|S|$

$J \quad$ Set of depots; elements indexed by $j=1,2, \ldots,|J|$

$P \quad$ Set of port terminals; elements indexed by $p=1,2, \ldots,|P|$

$R \quad$ Set of railway terminals; elements indexed by $r=1,2, \ldots,|R|$

$C$ Set of cleaning stations; elements indexed by $c=1,2, \ldots,|C|$

$V \quad$ Set of rail ship terminals; elements indexed by $v=1,2, \ldots,|V|$

$M$ Set of transport modes; elements indexed by $m=1,2, \ldots,|M|$

$K$ Set of container types; elements indexed by $k=1,2, \ldots,|K|$

$U$ Set of container conditions: $d$ (dirty) and $o$ (orderly)

\section{Parameters}

$D_{i k u}^{t} \quad$ Demand of customer $i$ at time period $t$ of type $k$ in condition $u$

$S_{s k u}^{t} \quad$ Supply of supplier $s$ at time period $t$ of type $k$ in condition $u$

$\tau_{l l^{\prime} m} \quad$ Transit time (hours) between origin $l$ and destination $l^{\prime}$ via mode $m$, where

$l, l^{\prime} \in I, S, J, P, R, C, V, E$

$\tau \quad$ Cleaning time at cleaning stations

$\Delta \quad$ Storage time allowed at intermodal terminals (railways, ports, and rail ships)

$\eta_{l l^{\prime} m}^{t} \quad$ Uncertain transportation capacity between $l$ and $l^{\prime}$ via mode $m$ at time period $t$ with regular uncertainty distribution $\Psi_{l l^{\prime} t m}$

$\eta_{l}^{t} \quad$ Uncertain storage capacity available at location $l$ at time period $t$ with regular uncertainty distribution $\Psi_{l t}$

$\xi_{l l^{\prime} m}^{t} \quad$ Uncertain unit transportation cost from $l$ to $l^{\prime}$ at time period $t$ via mode $m$ with regular uncertainty distribution $\Phi_{l l^{\prime} t m}$

$\xi_{l}^{t} \quad$ Uncertain unit storage cost at location $l$ at time period $t$ with regular uncertainty distribution $\Phi_{l t}$ 
$\epsilon_{i}^{t} \quad$ Uncertain emergency shipment cost for costumer $i$ at time period $t$ with regular uncertainty distribution $\phi_{i t}$

\section{Integer nonnegative decision variables}

$x_{l l^{\prime} m k u}^{t} \quad$ number of empty containers of type $k$ with condition $u$ to be arrived at destination $l^{\prime}$ via mode $m$ in the beginning of period $t$ from origin $l$, where $l, l^{\prime} \in I, S, J, P, R, C, V$

$z_{l k u}^{t} \quad$ number of empty containers of type $k$ in condition $u$ available at location $l$ in the beginning of time period $t$, where $l \in J, P, R, C, V$

$s h_{i k u}^{t} \quad$ number of stock-out empty containers (to be brought in from outside the system (leased, borrowed, or newly purchased) of type $k$ in condition $u$ for demand customer $i$ at time period $t$

\section{Chance-constrained model for ECR}

Empty containers must be repositioned between ports to ensure the continuity of shipping activity and to meet future transportation opportunities. However, significant sources of uncertainty may still affect this issue. This is because in many occasions, due to maintenance, economic reasons, or technical difficulties, we have lack of observed data about an unknown state of nature. For example, since loaded containers have greater priority than empty containers and unexpected transportation opportunities may arise, the residual transportation capacity for empty containers also fails to provide certain information. Moreover, the maximum number of empty containers that can be loaded and unloaded in ports is sometimes uncertain as well. Information on the number of empty containers requested in each port may also be imprecise, because unexpected transportation demands may arise. Moreover, the number of empty containers available in ports can also be uncertain, because we do not know precisely when they will be returned by import customers. In such cases where information is not sufficient, we have to invite some domain experts to evaluate their belief degree for events' occurrence. When only belief degrees are available (no samples), the estimated uncertainty distribution usually deviates far from the cumulative frequency. In this case, the uncertainty theory can be referred as one of the legitimate approaches (Liu 2007, 2010, 2012).

To formalize the discussion and develop a chance-constrained model, all ECR uncertain components are regarded as uncertain variables and the following modeling process is offered. It is worth noting that whenever there exists accurate data with high level of certainty based on enough proper historical data, one can easily substitute the corresponding uncertain component with a crisp value without any loss of generality and any change in the modeling process (see Remark 1).

Remark 1 According to laws of uncertainty programming, if, e.g., transportation cost $\xi_{l l^{\prime} m}^{t}=c_{l l^{\prime} m}^{t}$ is a certain number, then it can be regarded as a constant function on the uncertainty space, and therefore, it is concluded that $\Phi_{l l^{\prime} t m}^{-1}(\alpha)=c_{l l^{\prime} m}^{t}$ for any confidence level $\alpha \in(0,1)$ (Liu 2007, 2010, 2012).

Remark 2 Without loss of generality, we assume that all uncertain variables used in this work are independent and their uncertainty distributions are regular. Otherwise, a small perturbation can be given to get a regular distribution (Liu 2007).

The objective in the uncertain ECR problem is to minimize the total uncertain cost for empty container repositioning over a predefined certain horizon. The criteria of interest are the transportation costs between locations, storage costs, and the shortage costs associated with the stock-outs. We assume that the logistics supervisor wants to cut a budget $B$ and hopes the chance that the total cost exceeds the budget is kept below a confidence level $\alpha$. This is guaranteed by

$$
\begin{aligned}
& \mathscr{M}\left(\sum_{t \in N} \sum_{k \in K} \sum_{u \in U}\right. \\
& \left.\left[\sum_{\left(l, l^{\prime}\right) \in A} \sum_{m \in M} \xi_{l l^{\prime} m}^{t} x_{l l^{\prime} m k u}^{t}+\sum_{l \in A \backslash(I \cup S)} \xi_{l}^{t} z_{l k u}^{t}+\sum_{i \in I} \epsilon_{i}^{t} s h_{i k u}^{t}\right] \leq B\right) \\
& \geq 1-\alpha
\end{aligned}
$$

Internal and external depots and cleaning stations all offer storage. It is also possible to store at intermodal terminals. Chance constraint (2) ensures that the total number of containers to be stored at railway, port, and rail ship terminals will not exceed the storage limits in such locations with some given confidence level $\beta$.

$$
\mathscr{M}\left(\sum_{k \in K} \sum_{u \in U} z_{l k u}^{t} \leq \eta_{l}^{t}\right) \geq \beta \quad l \in\{R, P, V\}, t \in N
$$

All shipment modes are assumed to have a limited capacity. Chance constraint (3) ensures that total flow of all empty containers on each link cannot be exceeded with some given confidence level $\gamma$. 


$$
\mathscr{M}\left(\sum_{k \in K} \sum_{u \in U} x_{l l^{\prime} m k u}^{t} \leq \eta_{l l^{\prime} m}^{t}\right) \geq \gamma \quad\left(l, l^{\prime}\right) \in A, t \in N, m \in M
$$

Constraint (4) states that demand (of orderly containers) is satisfied during the prespecified planning horizon. If it is not possible to comply, containers will be brought from sources outside the system, denoted by $s h_{i k o}^{t}$.

$$
\sum_{l \in A \backslash I} \sum_{m \in M} x_{\text {limko }}^{t}=D_{i k o}^{t}-s h_{i k o}^{t} \quad i \in I, t \in N, k \in K
$$

Constraint (5) indicates that dirty empty containers available at supply customers sites must be shipped away at the same time period they are unloaded.

$$
\sum_{l \in A \backslash(S \cup I)} \sum_{m \in M} x_{s l m k d}^{t+\tau_{s l m}}=S_{s k d}^{t} \quad s \in S, t \in N, k \in K
$$

Inventories of dirty containers at cleaning stations are shown by constraint (6). These inventories are derived by considering the inflow of dirty containers to cleaning station and the outgoing flow of orderly containers.

$$
z_{c k d}^{t}=\sum_{l \in A \backslash(I \cup C)} \sum_{m \in M}\left[\sum_{\substack{t^{\prime} \in N \\ t^{\prime} \leq t}} x_{l c m k d}^{t^{\prime}}-\sum_{\substack{t^{\prime} \in N \\ t^{\prime} \leq t-\tau}} x_{l c m k d}^{t^{\prime}}\right]
$$$$
c \in C, t \in N, k \in K
$$

Constraint (7) shows the inventories of orderly (cleaned) containers at cleaning stations. These inventories can also be derived by obtaining the inflow and outflow of cleaned containers and the inflow of dirty containers that have been cleaned.

$$
\begin{aligned}
z_{c k o}^{t}= & \sum_{l \in A \backslash(I \cup S)} \sum_{m \in M} \sum_{t^{\prime} \in N, t^{\prime} \leq t} x_{l c m k o}^{t^{\prime}}-\sum_{l \in A \backslash S} \sum_{m \in M} \sum_{t^{\prime} \in N, t^{\prime} \leq t} x_{c l m k o}^{t^{\prime}+\tau_{c l m}} \\
& +\sum_{l \in A \backslash(I \cup C)} \sum_{m \in M} \sum_{t^{\prime} \in N, t^{\prime} \leq t-\tau} x_{l c m k d}^{t^{\prime}} \\
c & \in C, t \in N, k \in K
\end{aligned}
$$

Constraint (8) shows the number of empty containers of different types and conditions available at depots, railway, port, and rail ship terminals at each time period. Note that zero initial inventories of containers are assumed in our application.

$$
\begin{gathered}
z_{l k u}^{t}=\sum_{l^{\prime} \in A \backslash I} \sum_{m \in M}\left[\sum_{t^{\prime} \in N, t^{\prime} \leq t} x_{l^{\prime} l m k u}^{t^{\prime}}-\sum_{t^{\prime} \in N, t^{\prime} \leq t} x_{l l^{\prime} m k u}^{t^{\prime}+\tau_{l l^{\prime} m}}\right] \\
l \in\{J, P, R, V\}, t \in N, k \in K, u \in U
\end{gathered}
$$

Constraint (9) ensures that outgoing flow of empty containers of any type and condition at any time period cannot be more than the available empty containers at that period.

$z_{l k u}^{t} \geq \sum_{l^{\prime} \in A \backslash S} \sum_{m \in M} x_{l l^{\prime} m k u}^{t+\tau_{l l^{\prime} m}} \quad l \in\{J, P, R, C, V\}, t \in N, k \in K, u \in U$

The domain of decision variables prescribed in (10) guaranties that containers can flow in the network only until the end of prespecified planning horizon.

$x_{l l^{\prime} m k u}^{t}=0 \quad\left(l, l^{\prime}\right) \in A, t \notin N, m \in M, k \in K, u \in U$

With respect to flow conservation, there can be two different models of flow over time: with storage and without storage. In the model with intermediate storage of flow at intermodal terminals, it is possible to hold containers inventory for, e.g., $\Delta$ units of time before sending it onward. Storage means that the flow conservation is not satisfied at each time period because the amount of container flow arriving at a location at a given time can be different from the amount of container flow that leaves the location at that time. Thus, the flow conservation constraints are integrated over time to prohibit deficit at such locations:

$$
\begin{aligned}
& \sum_{l^{\prime} \in A \backslash I} \sum_{m \in M} x_{l^{\prime} l m k u}^{t} \geq \sum_{l^{\prime} \in A \backslash S} \sum_{m \in M} x_{l l^{\prime} m k u}^{t+\tau_{l^{\prime} m}} \\
& l \in\{P, R, V\}, t \in N, k \in K, u \in U
\end{aligned}
$$

In the model without intermediate storage, we require that equality holds in (11). To cope with ' $\Delta$ time units of waiting time', we note that for any time period $\delta$, the amount of flow that has arrived at a location by $\delta$ cannot be more than the amount of flow that has left the location before $\delta$. Therefore, if we view the arrivals and inventory as a queue, we may argue that containers can have a waiting time of at most $\Delta$ units at intermodal terminals:

$$
\begin{aligned}
z_{l k u}^{t} & \leq \sum_{l^{\prime} \in A \backslash S} \sum_{m \in M} \sum_{\delta \in N, \delta \leq \Delta} x_{l l^{\prime} m k u}^{t+\delta+\tau_{l l^{\prime} m}} \\
l & \in\{P, R, V\}, t \in N, k \in K, u \in U
\end{aligned}
$$

As we discussed, in practice, many parameters such as storage and capacities usually are not certainly determined. In this part, we employ uncertainty theory to deal with belief degrees. Given the distribution network $D N=G(L, A)$, a flow of empty containers $(x, z, s h)$ is feasible if it satisfies the foregoing constraints (1)-(12). Therefore, when a logistics supervisor wishes to cut the budget, $B$, and the total flow of all containers satisfies some chance constraints with some given confidence levels $\alpha, \beta$, and $\gamma$, the uncertain ECR problem can be stated as follows: 
$\left\{\begin{array}{cc}\min & B \\ \text { subject to: } & \\ \text { constraints } & (1)-(12) .\end{array}\right.$

(Model 1)

In the reminder of this section, we discuss how to obtain and solve an auxiliary $(\alpha, \beta, \gamma)$-ECR problem. Since $\xi_{l l^{\prime} m}^{t}$, $\xi_{l}^{t}$, and $\epsilon_{i}^{t}$ are all uncertain variables with regular distributions $\Phi_{l l^{\prime} t m}, \Phi_{l t}$, and $\phi_{l t}$, respectively, we can replace constraint (1) by constraint (13).

$$
\begin{aligned}
& \mathscr{M}\left(\sum_{t \in N} \sum_{k \in K} \sum_{u \in U}\right. \\
& \left.\left[\sum_{\left(l, l^{\prime}\right) \in A} \sum_{m \in M} \xi_{l l^{\prime} m}^{t} x_{l l^{\prime} m k u}^{t}+\sum_{l \in A \backslash(I \cup S)} \xi_{l}^{t} z_{l k u}^{t}+\sum_{i \in I} \epsilon_{i}^{t} s h_{i k u}^{t}\right] \geq B\right)=\alpha .
\end{aligned}
$$

Let us consider the ECR distribution cost as follows:

$$
\begin{aligned}
& \Upsilon(x, z, s h)=\sum_{t \in N} \sum_{k \in K} \sum_{u \in U} \\
& {\left[\sum_{\left(l, l^{\prime}\right) \in A} \sum_{m \in M} \xi_{l l^{\prime} m}^{t} x_{l l^{\prime} m k u}^{t}+\sum_{l \in A \backslash(I \cup S)} \xi_{l}^{t} z_{l k u}^{t}+\sum_{i \in I} \epsilon_{i}^{t} s h_{i k u}^{t}\right] .}
\end{aligned}
$$

Since $\Upsilon(\cdot)$ is an increasing function with respect to independent uncertain variables $\xi_{l l^{\prime} m}^{t}, \xi_{l}^{t}$, and $\epsilon_{i}^{t}$, it is an uncertain variable and its inverse uncertainty distribution $\Upsilon^{-1}$ exists (Liu 2007, 2010). As a result, constraint (13) boils down to the following constraint.

$$
\begin{aligned}
& \sum_{t \in N} \sum_{k \in K} \sum_{u \in U}\left[\sum_{\left(l, l^{\prime}\right) \in A} \sum_{m \in M}\left[\Phi_{l l^{\prime} t m}^{-1}(1-\alpha)\right] x_{l l^{\prime} m k u}^{t}\right. \\
& \left.+\sum_{l \in A \backslash(I \cup S)}\left[\Phi_{l t}^{-1}(1-\alpha)\right] z_{l k u}^{t}+\sum_{i \in I}\left[\phi_{i t}^{-1}(1-\alpha)\right] s h_{i k u}^{t}\right] \leq B .
\end{aligned}
$$

On the other hand, the uncertain transportation capacities $\eta_{l l^{\prime} m}^{t}$ and uncertain storage capacities $\eta_{l}^{t}$ are also regular with uncertainty distributions $\Psi_{l l^{\prime} t m}$ and $\Psi_{l t}$, respectively. Therefore, along the same lines as those for (14), we can transform constraints (2) and (3) to (15) and (16), respectively.

$$
\begin{aligned}
& \sum_{k \in K} \sum_{u \in U} z_{l k u}^{t} \leq \Psi_{l t}^{-1}(1-\beta) \quad l \in\{R, P, V\}, t \in N \\
& \sum_{k \in K} \sum_{u \in U} x_{l l^{\prime} m k u}^{t} \leq \Psi_{l l^{\prime} t m}^{-1}(1-\gamma) \quad\left(l, l^{\prime}\right) \in A, t \in N, m \in M
\end{aligned}
$$

Consequently, the uncertain ECR problem illustrated in Model 1 is equivalent to the following model. $\left\{\begin{array}{cc}\begin{array}{c}\text { min } \\ \text { subject to: }\end{array} & B \\ \text { constraints } & (4)-(12), \\ \text { constraints } & (14),(15),(16) .\end{array}\right.$

$(\text { Model 1) })^{\prime}$

Finally, it is easy to observe that Model 1 ' can be re-stated as a well-defined, solvable, deterministic $(\alpha, \beta, \gamma)-E C R$ problem as follows:

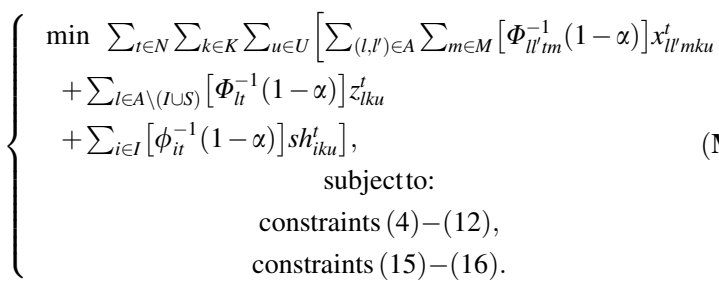

$(\text { Model1 })^{\prime \prime}$

Therefore, given the distribution network $D N=G(L, A)$ and the confidence levels $\alpha, \beta$, and $\gamma$, we refer to the solution of Model 1 " as the $(\alpha, \beta, \gamma)$-optimal ECR solution for the uncertain ECR problem (presented by Model 1). We have then established the following results.

Theorem 1 Let $D N=(L, A)$ represent the distribution network of the uncertain ECR problem and suppose that $\xi_{l l^{\prime} m}^{t}, \xi_{l}^{t}, \epsilon_{i}^{t}, \eta_{l l^{\prime} m}^{t}$, and $\eta_{l}^{t}$ denote the independent uncertain variables with regular distributions $\Phi_{l l^{\prime} t m}, \Phi_{l t}, \phi_{l t}, \Psi_{l l^{\prime} t m}$, and $\Psi_{l t}$, respectively, associated with the parameters of the network. The uncertain ECR problem is equivalent to the well-defined deterministic $(\alpha, \beta, \gamma)$-ECR problem presented by Model 1 ", provided that the confidence levels $\alpha, \beta, \gamma$ are given.

Theorem 1 yields that the optimal solution of the uncertain ECR problem is actually the $(\alpha, \beta, \gamma)$-optimal ECR solution obtained from Model 1 ". It also presents a simple way to obtain the uncertainty distribution of the cost of repositioning of empty containers. To this aim, it is enough to choose a number of different $\alpha, \beta$, and $\gamma$ and solve Model 1 " repeatedly. We also highlight that Model $\mathbf{1}^{\prime \prime}$ is decreasing with respect to $\alpha$ and non-decreasing with respect to $\beta$ and $\gamma$.

\section{Computational study and experiments}

A computational study with real data is employed to demonstrate the functionality of the model. The case-study company is a European logistic service provider (ELSP) that transports bulk products loaded in containers and owns circa 35000 containers. The case-study problem deals with one main part of the company's whole distribution network that involves approximately $20 \%$ of its total market. To account for variability in demand and to investigate the model's 
performance, we examine the proposed model under different planning horizons using one-year actual historical shipping patterns performed by the company, with key practical considerations such as delivery time periods and intermodal transports. Computational experiments show the functionality of the model and suggest that potential distribution cost savings of about $6-10 \%$ would be possible to achieve through flow and modality alterations. Furthermore, to highlight certain features of the model and to reveal how the distribution cost depends on the model's parameters, we present a sensitivity analysis and we investigate the effect of the parameters on the container management.

We start by describing the general settings applied in our computational experiments. Each instance is solved on a personal computer with Intel Core i7-5600U processor, clock rate of $2.6 \mathrm{GHz}$, and $16 \mathrm{~GB}$ RAM. We used the optimization modeling language AIMMS and the CPLEX solver in order to solve our instances. The data used have been collected from the database of the ELSP's transportation planning tool (for the period of one year), which comprises the total planning actions performed by the ELSP company within Europe. Although the mathematical model is not exactly a network flow model, the coefficient matrices tend to be sparse so that solution times have been short fast for small- and medium-sized instances. Figure 2 and Table 2 give an overview of the topology and statistics of the distribution network under study. Table 3 also shows customers' locations along Europe and their tributaries, classified by countries and regions.

The data obtained from the company include time-dependent demands over one year for all customers, transportation costs over links for all transportation modes, cleaning times, storage times, storage costs, transit capacities for all modes, and storage capacities at intermodal terminals. Transportation costs and transit times (lead times) for shipments to be carried out via vessel and train were derived by calculating the average price and transit time of each origin-destination pair. Distances between each origin-destination pair were calculated and related to the average speed of a truck $(60 \mathrm{~km} / \mathrm{h})$ in order to derive the transit times for shipments over roads. The storage capacities at intermodal terminals were supposed to represent the only sources of uncertainty, controlling the values taken by the other uncertain parameters. Uncertainty distributions about the capacities over the whole planning horizon are provided by expert-based opinions, and the confidence levels $\alpha, \beta$, and $\gamma$ are provided by the logistics supervisor. The domain experts are presumed to be independent.

Based on the expert-based opinions, we decided to mostly employ linear, discrete, empirical, and zigzag uncertainty distributions (see Liu 2007, 2010). To construct our distributions, some parameters should have been estimated. All such information was gathered from domain experts through qualitative and quantitative analysis, interviews, and observations. For more information on uncertainty distributions and exploring the recent developments of uncertainty theory, the reader may consult Liu (2007). As we discussed earlier, when for some uncertain parameter like $\xi_{l l^{\prime} m}^{t}$ we have an exact (crisp) value of $c_{l l^{\prime} m}^{t}$, we can set $\Phi_{l l^{\prime} t m}^{-1}(1-\alpha)=c_{l l^{\prime} m}^{t}$ for any $\alpha \in(0,1)$ in the model. The same is true for any other parameter of exact

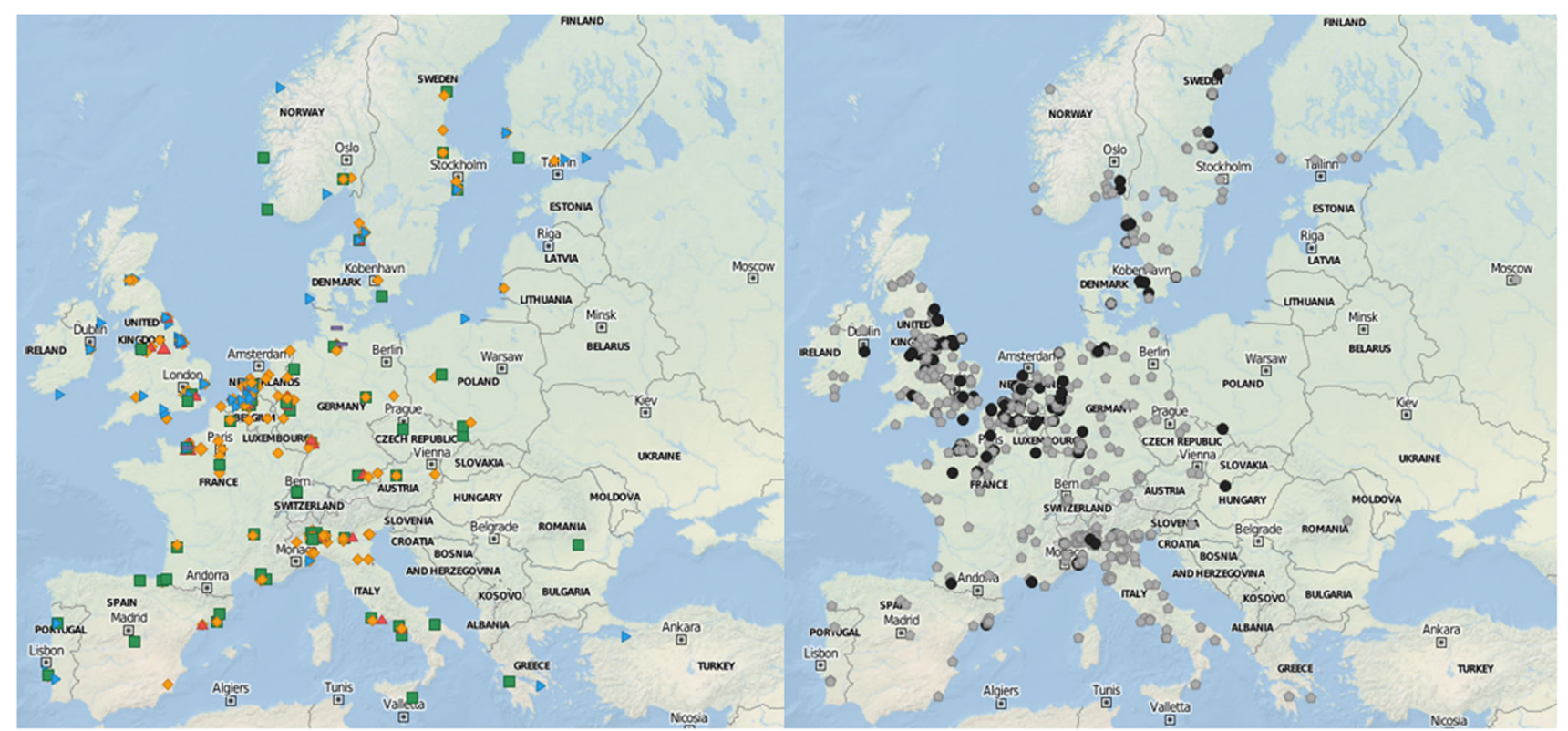

Fig. 2 (Left) depots, cleaning stations, railway, port and rail ship terminals; (right) demand and supply customer locations 
Table 2 Statistics of the ELSP company's distribution network

\author{
Depots: $38(4+34)$ \\ (Internal + external) \\ Cleaning stations: $138(8+130)$ \\ (Internal + external) \\ Rail ship terminals: 15
}

Supply customers: 1196

Demand customers: 487

Railway terminals: 98

Links/sections 14,590
Port terminals: 93

Total number of locations 2065
Table 3 Countries and regions of the ELSP distribution network

\begin{tabular}{|c|c|c|c|c|}
\hline Country & Region 1 & Region 2 & Region 3 & Region 4 \\
\hline \multicolumn{5}{|l|}{ Austria } \\
\hline \multicolumn{5}{|l|}{ Belgium } \\
\hline \multicolumn{5}{|l|}{ Bulgaria } \\
\hline \multicolumn{5}{|l|}{ Switzerland } \\
\hline Germany & East & & & \\
\hline Denmark & North & West & South & \\
\hline Spain & Central & North-East & North-West & \\
\hline Finland & North & South & & \\
\hline France & North-West & South-East & Venissieux & \\
\hline England & North-East & North-West & South & \\
\hline \multicolumn{5}{|l|}{ Scotland } \\
\hline Ireland & North & South & & \\
\hline Italy & Central & North-East & North-West & South \\
\hline \multicolumn{5}{|l|}{ Netherlands } \\
\hline \multicolumn{5}{|l|}{ Norway } \\
\hline \multicolumn{5}{|l|}{ Poland } \\
\hline Portugal & North & South & & \\
\hline \multicolumn{5}{|l|}{ Russia } \\
\hline Sweden & North & East & West & South \\
\hline Slovenia & & & & \\
\hline
\end{tabular}

values. This means that the proposed model is a generic model that can also cover deterministic problems.

In addition, the network topology of the case-study problem is utilized to create random instances with random parameters, and the model is also evaluated on these instances. We randomly selected a combination of different customers and compared the real-life situation to the proposals suggested by the model in order to investigate the behavior of the model. The sensitivity analysis employs a set of data from our case study and randomly generated data to highlight certain features of the model and provide some insights regarding its behavior.

The company's motivation to use our model was to reduce the distribution costs by improving the transport modality over links, so there was no budget restriction. Hence, our experiments are mainly based on Model $1^{\prime \prime}$. Table 4 shows the performance of the model for some instances with different planning horizons, fixed transportation and storage costs, and with fixed confidence levels $\beta=0.9999$ and $\gamma=0.9999$. The computational experiments show that the model finds good-quality solutions and demonstrate that cost improvements could be achieved in the network.

The first sensitivity analysis concerns the planning horizon. The objective is to show what effects different discretizations of the planning horizon may have on operational costs, modality utilization, and computational performance. Although the length of the planning horizon remains constant at 4 days ( $96 \mathrm{~h}$ ), the discretization of the time periods varies. The latter is of interest since time discretization methods are used to make the problem solvable within a certain amount of time. Although we keep the length of the planning horizon constant, we generate different discretization of the planning horizon by changing the length of the time periods (see, e.g., Fig 3). Subsequently, the whole system and its parameters are modified to fulfill the company's requirements. Table 5 partially shows that the discretization can have substantial impact on the solution time, the size of the problem (number of variables and constraints), and travel mode usage.

Figure 4 indicates that, in our sample, the cost function usually tends to linearly increase as the number of time periods becomes larger. However, while comparing the total cost, we conclude that the cost will be constant after some point. Figure 4 also indicates that the computational time increases rapidly as the planning horizon discretization becomes more realistic. Instance 5 could not be solved since the solver terminated the process. The process was terminated since the memory of 16 GB RAM was insufficient for this instance. The 'out of memory error' occurred in the 'generation phase' of AIMMS and CPLEX could never initialize.

To further evaluate the sensitivity of the model, we investigate the effects of length of the planning horizon and
Table 4 Model's performance and achievements

\begin{tabular}{llll}
\hline Settings & Instance 1 $(\%)$ & Instance 2 $(\%)$ & Instance 3 $(\%)$ \\
\hline Total cost savings & 6.54 & 6.29 & 10.3 \\
\hline
\end{tabular}


Table 5 Distribution cost, modality utilization, and elapsed computational time for an instance with different discretizations \# Supply sites: 292, \# Demand sites: 170, Initial inventory: 0, Max capacity $=5000$

\begin{tabular}{llllll}
\hline Settings & Instance 1 & Instance 2 & Instance 3 & Instance 4 & Instance 5 \\
\hline \# Time periods & 4 & 16 & 24 & 32 & 48 \\
\# Constraints & 138,468 & 553,579 & 830,013 & $1,106,352$ & $1,925,630$ \\
\# Variables & 601,761 & $2,407,041$ & $3,610,561$ & $4,814,081$ & $8,376,501$ \\
Total cost & 37,509 & 40,843 & 41,350 & 41,396 & - \\
Trans. cost & 23,758 & 26,803 & 27,122 & 27,129 & - \\
Storage cost & 13,751 & 14,040 & 14,228 & 14,267 & - \\
Shortages & 0 & 0 & 0 & 0 & - \\
Modality util. (\%) & $100 / 0 / 0$ & $100 / 0 / 0$ & $100 / 0 / 0$ & $99 / 0 / 1$ & - \\
Road/Rail/Sea & & & & 2562.31 & $>1000.00$ \\
Elapsed time for AIMMS/CPLEX & 261.63 & 912.47 & 1596.56 & & Tormal \\
$\quad$ (s) & Normal & Normal & Normal & completion & completion \\
Status & completion & completion & comer by & solver \\
\hline
\end{tabular}

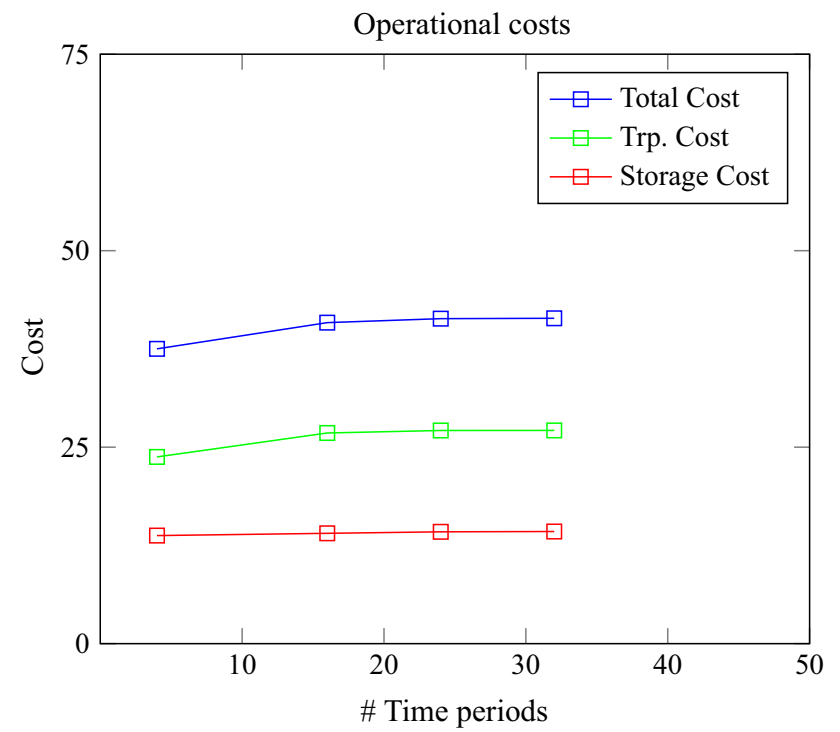

Fig. 3 Cost comparison under different time discretizations

two different amounts of initial inventory on the optimal plans. We compare the effects of 4-day, 7-day, and 21-day planning horizons on modality utilization and different logistics cost. This analysis is presented in Table 6.

Regardless of the amount of initial inventory, Table 6 reveals that the total cost is an increasing function of the length of the planning horizon, that is quite intuitive. However, we have observed that although the 7-day, and 21-day models consider longer planning horizons, the optimal solutions only suggest a higher cost during the early periods. We have observed that setting a good value for the planning horizon can highly depend on the topology

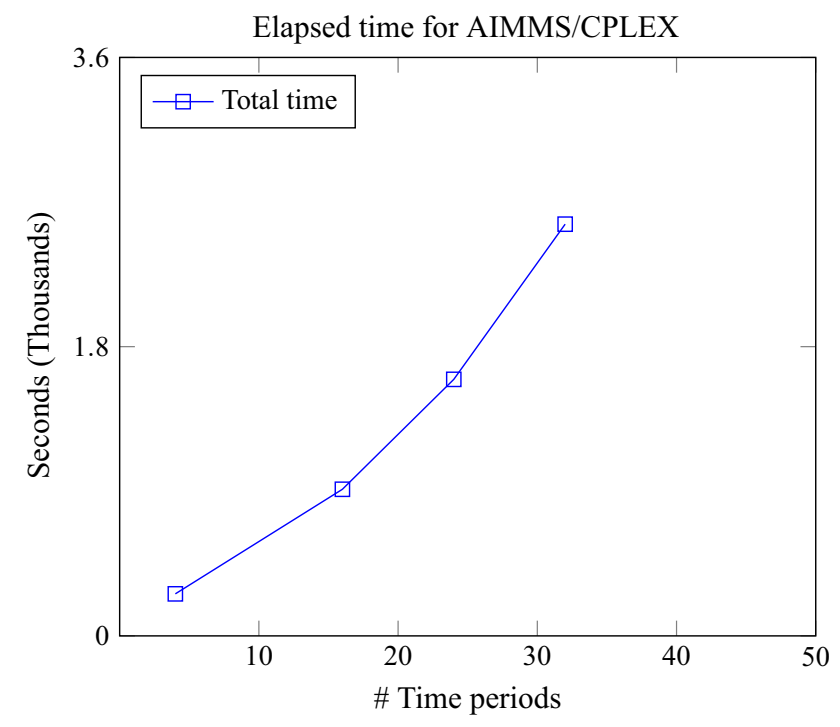

Fig. 4 Computational time comparison under different time discretizations

and the size of the network under study and that a longer planning horizon (used on a rolling basis) can offer more efficient empty container distribution plans (but not necessary cheaper), especially for the earlier periods. However, the advantages of using a long planning horizon might be little for a shipping company that has many suppliers, as the distribution system of such companies may have small end-of-horizon effects. These observations are also shown in Fig. 5.

Focusing on the instances with 0 initial inventory and the results of the 4-day, 7-day and 21-day models, some considerable allocation impacts can be noted. We also 
Table 6 Operational costs and modality utilization as a result of different planning horizons and initial inventory

\begin{tabular}{|c|c|c|c|}
\hline \multicolumn{4}{|c|}{ Supp. and dem. (in the first 4 time periods): 361,170 , Max capacity $=5000$} \\
\hline Settings & Instance 1 & Instance 2 & Instance 3 \\
\hline \multicolumn{4}{|c|}{ Initial inventory clean: 0 , initial inventory dirty: 0} \\
\hline \# Time periods & 4 & 7 & 21 \\
\hline Total cost & 53,884 & 61,874 & 89,048 \\
\hline Trans. cost & 52,946 & 60,895 & 87,748 \\
\hline Storage cost & 938 & 979 & 1300 \\
\hline \# Shortages & 0 & 0 & 0 \\
\hline Modality util. (\%) & $91.9 / 3.3 / 4.8$ & $90.2 / 4 / 5.8$ & $82.9 / 6.8 / 10.3$ \\
\hline \multicolumn{4}{|l|}{ Road/Rail/Sea } \\
\hline \multicolumn{4}{|c|}{ Initial inventory clean: 399, initial inventory dirty: 510} \\
\hline \# Time periods & 4 & 7 & 21 \\
\hline Total cost & 63,990 & 65,711 & 75,394 \\
\hline Trans. cost & 27,906 & 37,360 & 51,457 \\
\hline Storage cost & 36,084 & 28,351 & 23,937 \\
\hline \# Shortages & 0 & 0 & 0 \\
\hline Modality util. (\%) & $100 / 0 / 0$ & $99.7 / 0.3 / 0$ & $99.7 / 0.3 / 0$ \\
\hline Road/Rail/Sea & & & \\
\hline
\end{tabular}

Fig. 5 Operational costs with 0 and high initial inventory

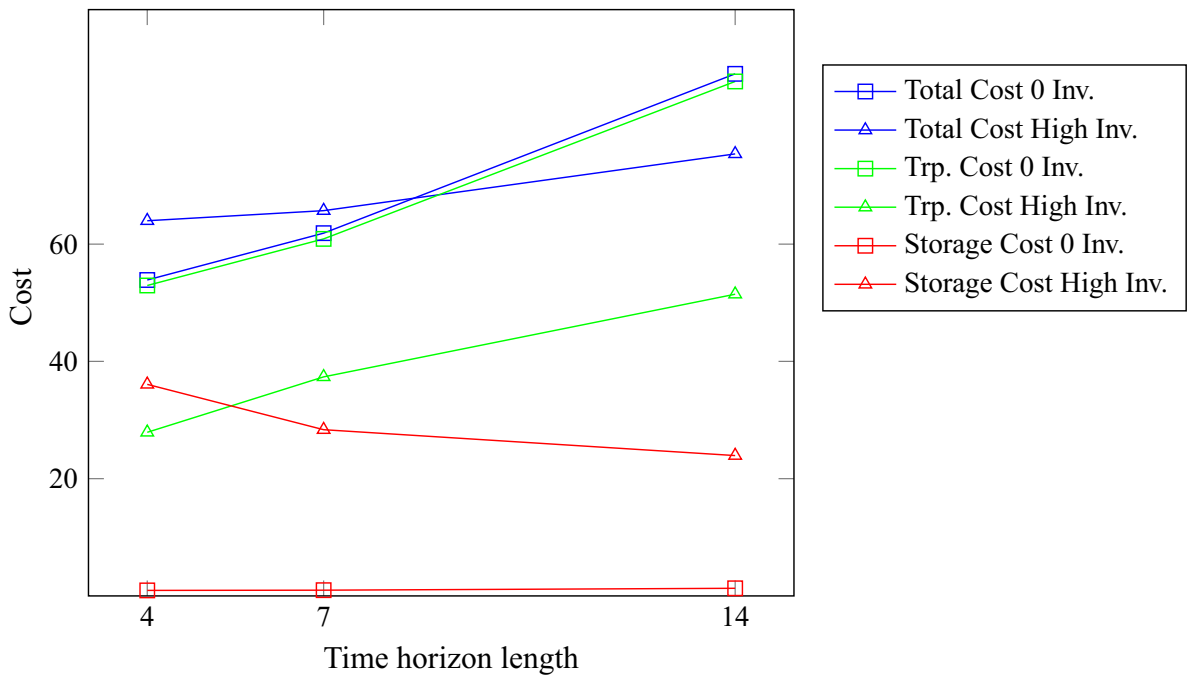

observed that the 7-day and 21-day models propose a lower utilization of road over the first 4 days compared to the 4-day model. Containers not needed for meeting the demand in the next four days have been mainly transported via slower modes to other regions where demand may arise in future time periods. On the other hand, the results from instances with high inventories suggest a high utilization of road regardless of the length of the planning horizon. High initial inventory allows demand to be satisfied from facilities close to the demand sites. i.e., intermodal transportations are not necessary. Figure 6 illustrates a decreasing storage cost function and increasing transportation cost function as a result of changes in the length of the planning horizon. It is observed that longer planning horizon usually allows transportation with longer transit times, hence suggesting more transportation and less storage. Inventories of empty containers are usually repositioned to nearby facilities with relatively lower storage cost.

The next sensitivity analysis concerns the capacity restriction on transportation modes over links and time periods. To do so, they are set to crisp values, i.e., $\eta_{l l^{\prime} m}^{t}=C_{l l^{\prime} m}^{t}$, and we also set $\gamma=1$. Hence, constraint (16) will be of following form:

$\sum_{k \in K} \sum_{u \in U} x_{l l^{\prime} m k u}^{t} \leq C_{l l^{\prime} m}^{t} \quad\left(l, l^{\prime}\right) \in A, t \in N, m \in M$.

The aim is to investigate how the distribution costs and the modality utilizations are influenced by this condition. The results are presented in Table 7, Figs. 7 and 8. 
Fig. 6 Modality utilization with 0 and high initial inventory

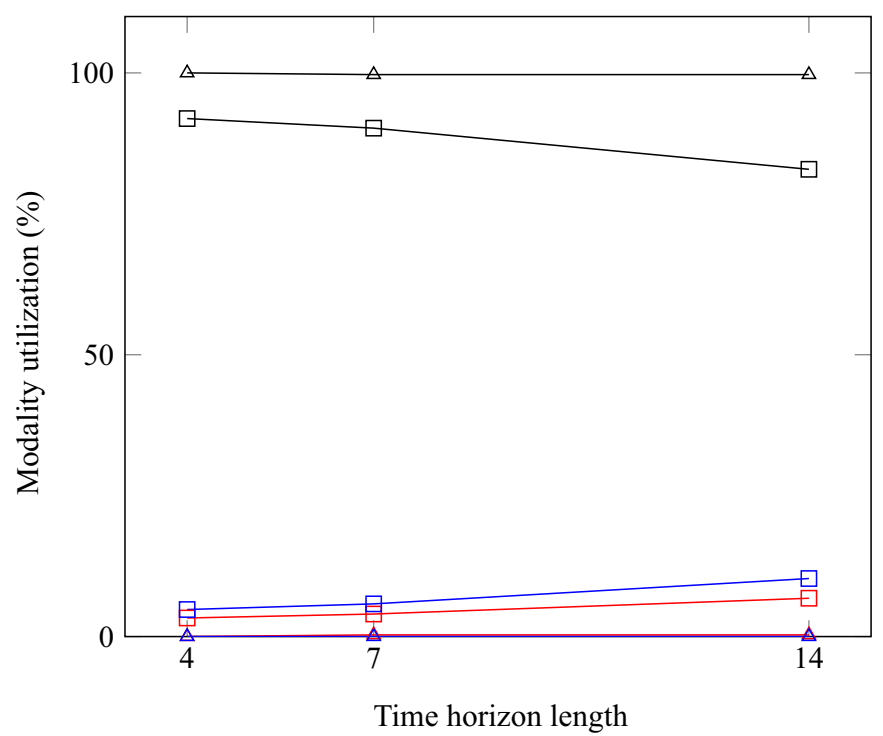

$\square$ Road 0 Inv. $\triangle$ Road High Inv. $\square$ Rail 0 Inv. $\triangle$ Rail High Inv. $\square$ Sea 0 Inv. $\triangle$ Sea High Inv.
Table 7 Costs and modality utilizations in terms of transportation capacities $\left(C_{l l^{\prime} m}^{t}\right)$

Supply: 265, demand: 170, initial inventory: 0, \# time periods: 4

\begin{tabular}{llllll}
\hline Settings & Instance 1 & Instance 2 & Instance 3 & Instance 4 & Instance 5 \\
\hline$C_{l l^{\prime} m}^{t}$ (increase in \%) & 0 & 10 & 20 & 30 & 40 \\
Total cost & 51,064 & 50,910 & 50,800 & 50,751 & 50,704 \\
Trans. cost & 50,239 & 50,083 & 49,970 & 49,920 & 49,870 \\
Storage cost & 826 & 828 & 830 & 831 & 834 \\
\# Shortages & 0 & 0 & 0 & 0 & 0 \\
Modality util. (\%) & $91.7 / 3.9 / 4.3$ & $91.3 / 3.9 / 4.6$ & $91.2 / 3.8 / 5$ & $91 / 4 / 5$ & $91 / 3.8 / 5.2$ \\
Road/Rail/Sea & & & & & \\
\hline
\end{tabular}

Total cost and transportation cost

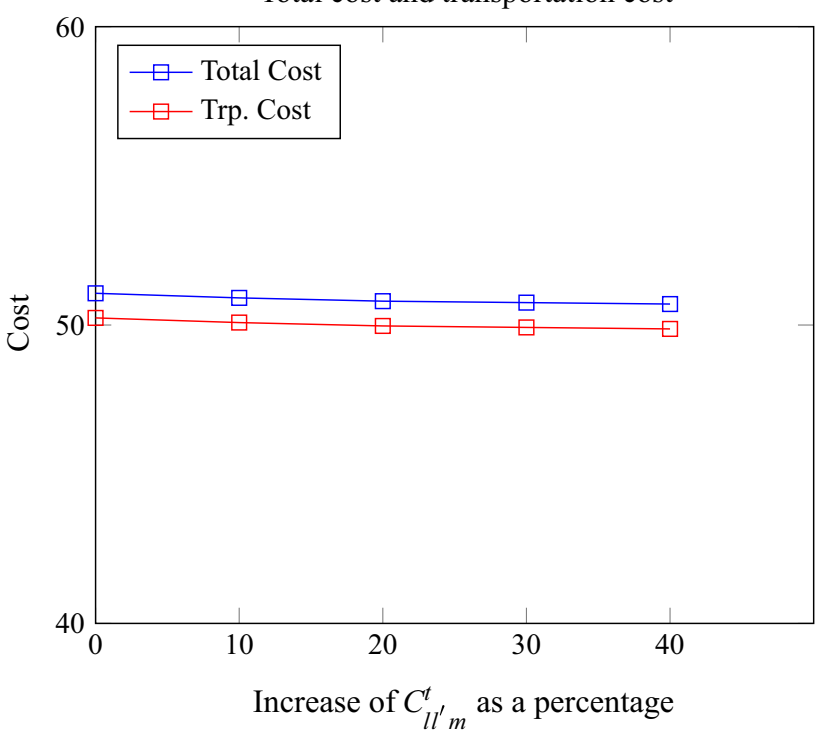

Storage cost

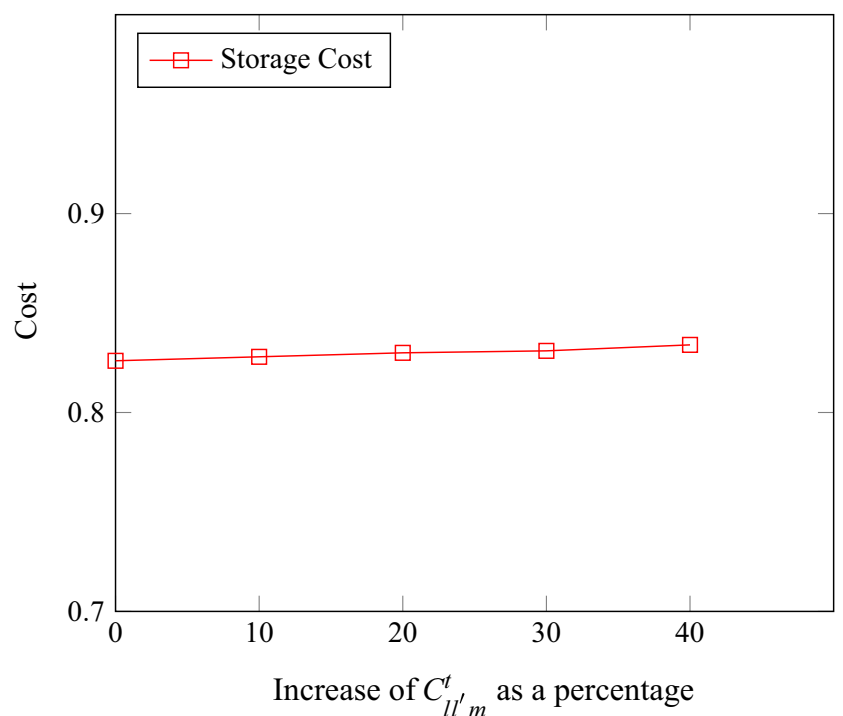

Fig. 7 Cost as a result of increasing $C_{l l^{\prime} m}^{t}$ 
Road utilization

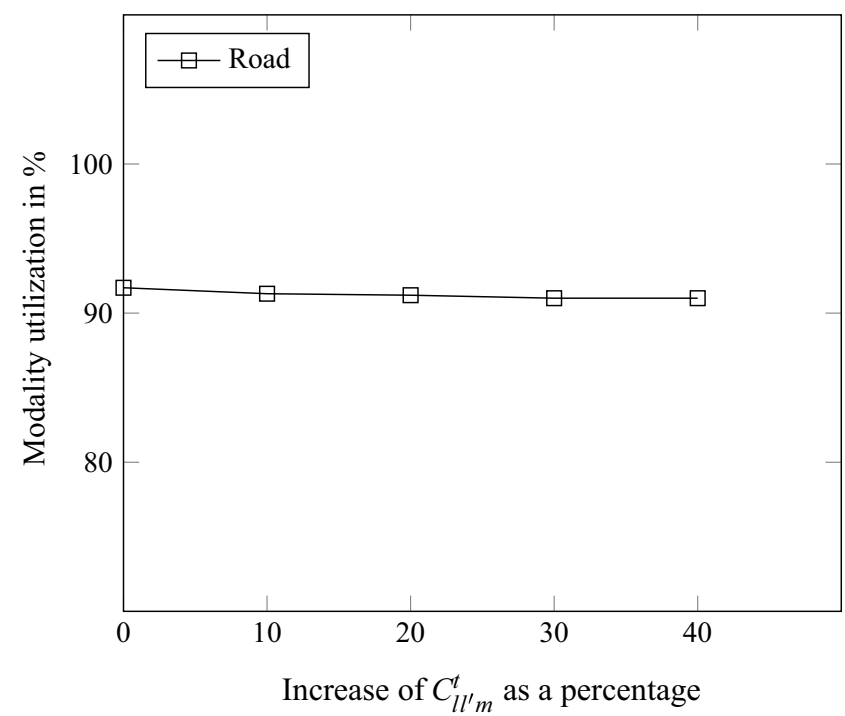

Rail and sea utilization

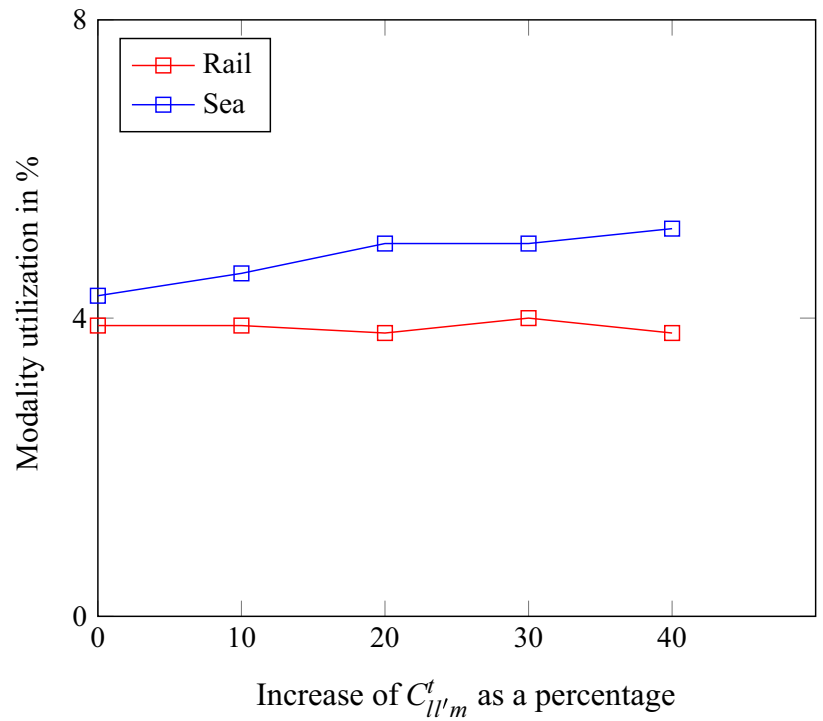

Fig. 8 Modality utilization as a result of increasing $C_{l l^{\prime} m}^{t}$

Table 8 Cost and modality utilizations in terms of allowed storage time at intermodal terminals

\begin{tabular}{llllll}
\hline Supp.: 265, Dem.: & 170, initial inventory: 0, \# periods: & 21, Max capacity $=5000$ & \\
\hline Settings & Instance 1 & Instance 2 & Instance 3 & Instance 4 & Instance 5 \\
\hline$\Delta$ & 0 & 1 & 2 & 3 & 4 \\
Total cost & 955,117 & 954,110 & 945,584 & 934,718 & 930,831 \\
Trans. cost & 810,709 & 806,818 & 801,542 & 790,397 & 785,505 \\
Storage cost & 144,408 & 147,292 & 144,042 & 144,321 & 145,326 \\
\# Shortages & 38 & 22 & 0 & 0 & 0 \\
Shortages (\%) & 0.37 & 0.2 & 0 & 0 & 0 \\
Modality util. (\%) & $100 / 0 / 0$ & $90.8 / 4.5 / 4.7$ & $91.0 / 4.7 / 4.3$ & $89.0 / 4.8 / 6.2$ & $89.1 / 5.1 / 5.8$ \\
Road/Rail/Sea & & & & & \\
\hline
\end{tabular}
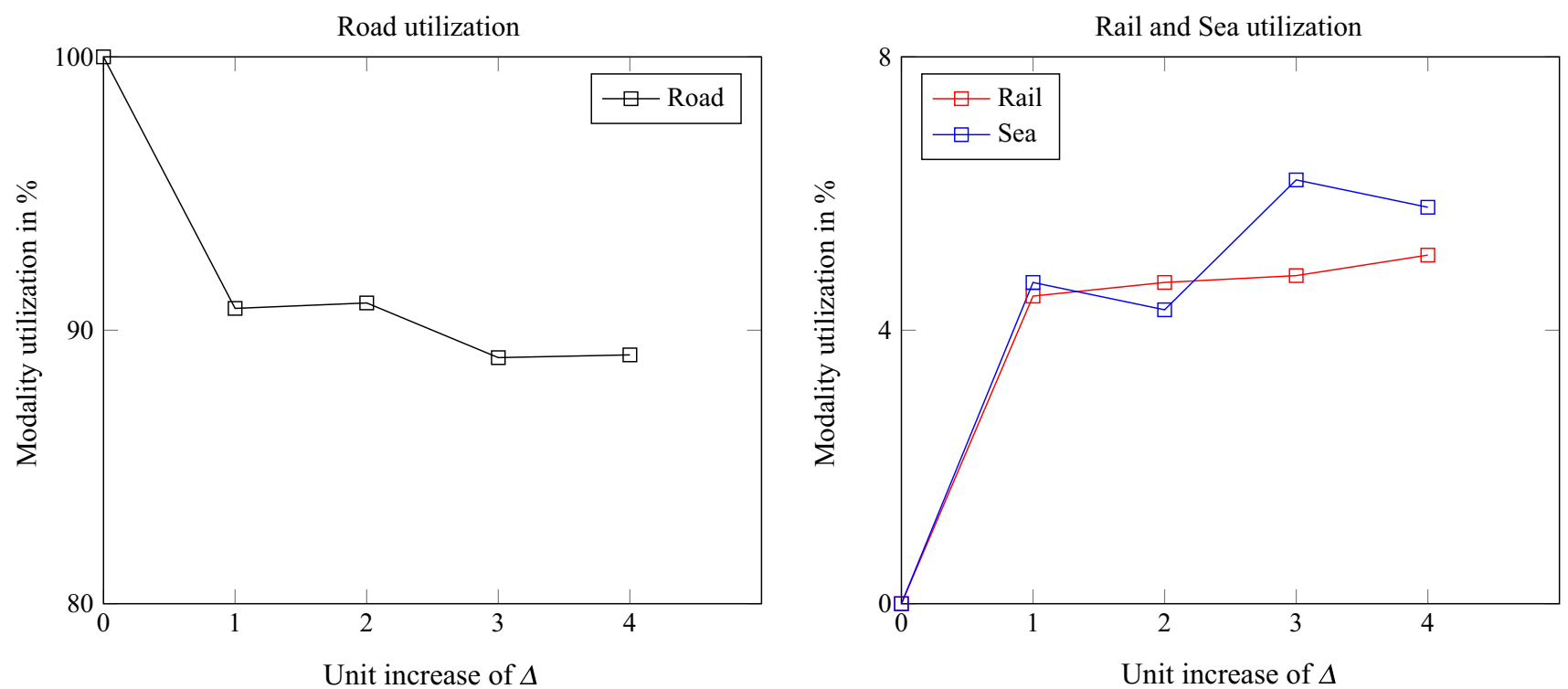

Fig. 9 Modality utilization as a result of increase in $\Delta$ 
Table 7 and Fig. 7 demonstrate that the total cost tends to decrease as we are allowing higher transportation capacity over links. Slower and cheaper modes are utilized more when the transportation capacities are extended. This can be seen through Fig. 8. This explains the decreasing transportation cost function. Transportation via train and sea can cause a relatively higher storage cost at intermodal terminals. As a result, sometimes, the storage cost slightly increases (Table 7).

We also address the storage time $(\Delta)$ at intermodal terminals. The aim is to investigate what impact allowed storage time at intermodal terminals may have on the distribution cost and the modality utilization.

When storage at intermodal terminals is not allowed $(\Delta=0)$, we expect a low utilization of transportation via rail and sea. Table 8 and Fig. 9 confirm this expectation. Even though the storage cost tends to fluctuate as we allow longer storage time at intermodal terminals, the total cost tends to be decreasing (see Fig. 10). The slower and cheaper modes are used more, and so the transportation costs tend to decrease.

As discussed in Theorem 1, given the confidence levels $\alpha, \beta$, and $\gamma$, uncertainty programming offers a simple way to obtain the uncertainty distribution of the optimal ECR cost. It is done by converting the uncertain ECR problem into an $(\alpha, \beta, \gamma)$-ECR problem and solving Model 1 " for different values of $\alpha, \beta$, and $\gamma$. It should be highlighted that as $\alpha$ increases, the total ECR cost will decrease (see Fig. 11). This is due to the relation between the unit transportation and storages costs and the inverse

Total cost ans transportation cost

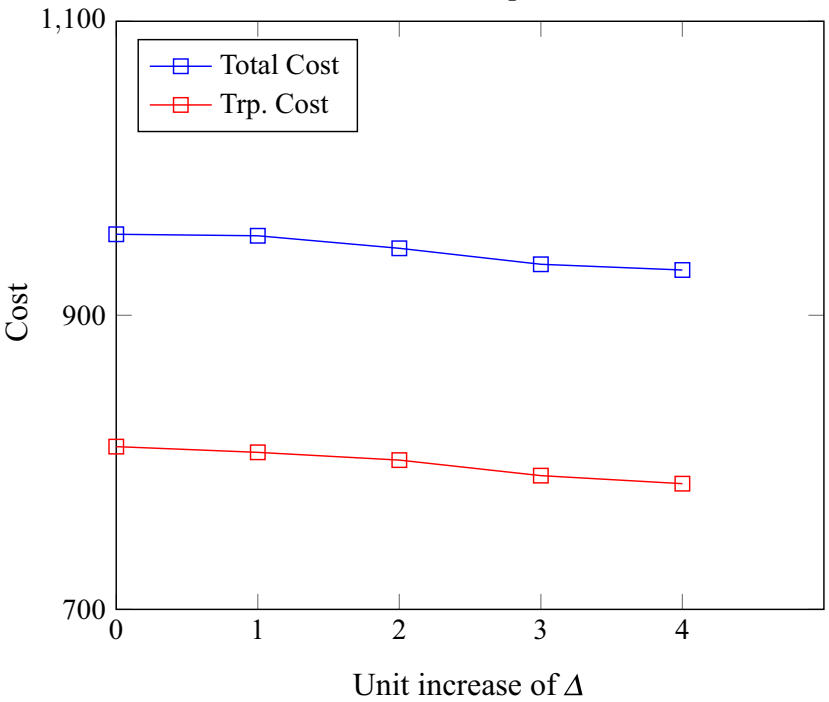

Fig. 10 Cost as a result of increase in $\Delta$

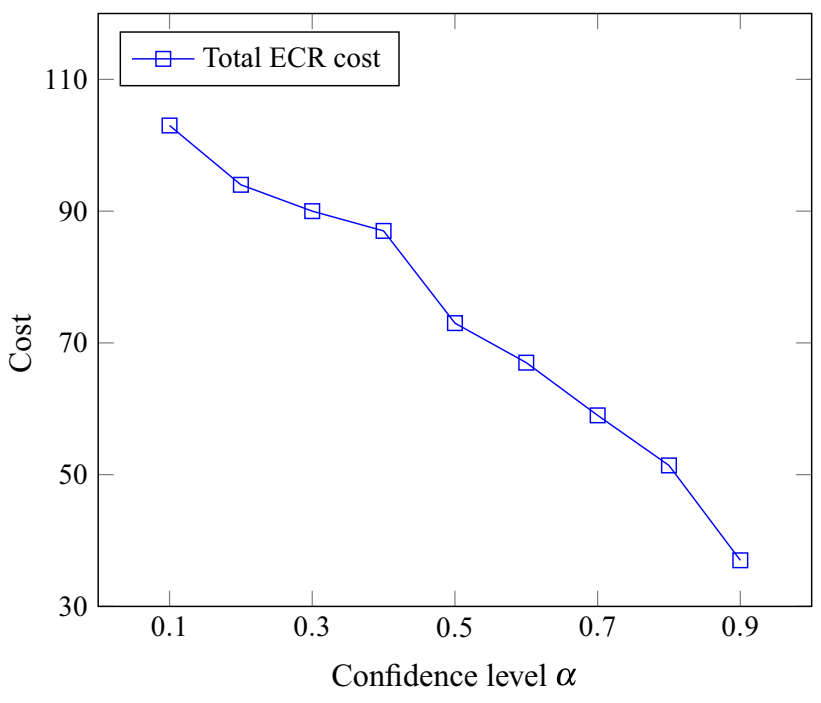

Fig. 11 The optimal ECR cost uncertainty distribution $(\beta=\gamma=0.9999)$

uncertainty distributions of the uncertain cost variables (see the objective function in Model 1 ").

In addition, Model 1 " is non-decreasing with respect to $\beta$, and $\gamma$. This is intuitive. Because when the confidence levels $\beta$ and $\gamma$ increase, the model has to find an optimal ECR solution in a smaller feasible set, so the total ECR cost either increases or stays the same. Hence, by solving the problem for different values of $\beta$ and $\gamma$ we also get to estimate the uncertainty distribution of optimal ECR cost with respect to these parameters.

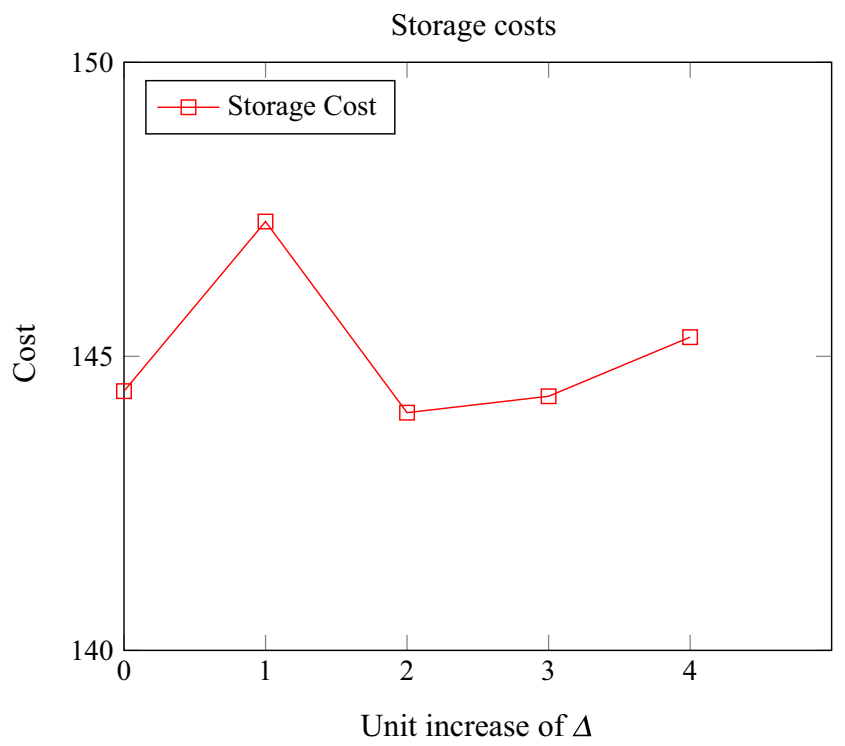




\section{Conclusion}

Based on Liu's uncertainty theory, this paper addresses the repositioning of empty containers (of multiple types) in time-dependent, intermodal distribution network of an anonymous international European logistic service provider company (denoted by ELSP) in discrete-time settings under uncertainty and data shortage. The company transports bulk products (oil, gas, petroleum, chemical, foodstuff, etc.) loaded in containers via road, rail, and sea needing to properly reposition its empty containers over different types of ports.

Exploiting the operational law of independent uncertain variables, the uncertain ECR problem is originally modeled and analyzed in the framework of uncertainty programming. In order to solve the uncertain ECR problem, a new auxiliary $(\alpha, \beta, \gamma)$-ECR model is proposed and its equivalence relation with uncertain ECR problem is demonstrated. By exploiting this relation, the original uncertain ECR problem is solved and the uncertainty distribution of the optimal logistics cost is obtained.

The case-study problem has been dealing with one main part of the company's whole distribution network that involves approximately $20 \%$ of its total market, which is used to illustrate the interest and functionality of the model. Computational experiments show the functionality of the model and suggest that potential distribution cost savings of $6-10 \%$ would be possible to achieve through modality alteration over links of the distribution network. Furthermore, to highlight certain features of the model and the effect of the model's parameters on empty container management, an extensive sensitivity analysis is presented. The proposed model captures many time-varying parameters, which makes it possible to quantify the trade-offs between different criteria of the ECR problem. The model includes many practical considerations needed for ECR distribution networks: meeting demand and supply requirements, multimodal transports, cleaning processes, transport and storage capacity, internal and external locations, various types of ports, terminals, and depots, etc. However, there are several possibilities for extending the model proposed in this study.

We note that proposed model is concerned with one of the main objectives of the ECR distribution networks, viz. the distribution cost. However, there can be some other aspects and criteria that could be taken into account, e.g., profit, power, customer's credit performance, and objectives of various business divisions (such as marketing, sales, distribution, planning, and purchasing). Hence, developing a unified and rigorous structure that can capture all synergies, criteria, and trade-offs could be worthy of further exploration. To include multiple criteria, the use of analytical hierarchy process (AHP) and non-preemptive weighted goal programming is highly recommended. Including short- and long-term leasing in the model could be another direction for future research. Moreover, it might be worthwhile to consider the uncertain nature of transit times in the ECR problem as well. One future research endeavor could be to integrate the loaded and empty containers flow decisions in a single integrated model. Finally, exploring the use of parallel computing and decomposition algorithms, such as Bender's decomposition, to cope with larger instances could be one other area for further expansion.

Open Access This article is distributed under the terms of the Creative Commons Attribution 4.0 International License (http://creative commons.org/licenses/by/4.0/), which permits unrestricted use, distribution, and reproduction in any medium, provided you give appropriate credit to the original author(s) and the source, provide a link to the Creative Commons license, and indicate if changes were made.

\section{References}

Ahmad Hosseini S, Şahin G, Ünlüyurt T (2017) A penalty-based scaling algorithm for the multi-period multi-product distribution planning problem. Eng Optim 49(4):583-596

Bhattacharya A, Kumar S, Tiwari M, Talluri S (2014) An intermodal freight transport system for optimal supply chain logistics. Transp Res Part C Emerg Technol 38:73-84

Bin W, Zhongchen W (2007) Research on the optimization of intermodal empty container reposition of land-carriage. J Transp Syst Eng Inf Technol 7(3):29-33

Braekers K, Janssens GK, Caris A (2011) Challenges in managing empty container movements at multiple planning levels. Transp Rev 31(6):681-708

Brouer BD, Pisinger D, Spoorendonk S (2011) Liner shipping cargo allocation with repositioning of empty containers. INFOR Inf Syst Oper Res 49(2):109-124

Chen T (1999) Yard operations in the container terminal-a study in the unproductive moves'. Marit Policy Manag 26(1):27-38

Cheung RK, Chen CY (1998) A two-stage stochastic network model and solution methods for the dynamic empty container allocation problem. Transp Sci 32(2):142-162

Chiadamrong N, Piyathanavong V (2017) Optimal design of supply chain network under uncertainty environment using hybrid analytical and simulation modeling approach. J Ind Eng Int 13(4):465-478

Choong S, Kutanoglu CEM (2002) Empty container management for intermodal transportation networks. Transp Res Part E Logist Transp Rev 38(6):423-438

Crainic T, Gendreau M, Dejax P (1993) Dynamic and stochastic models for the allocation of empty containers. Oper Res 41(1):102-126

Deidda L, Di Francesco M, Olivo A, Zuddas P (2008) Implementing the street-turn strategy by an optimization model. Marit Policy Manag 35(5):503-516

Dejax P, Crainic T (1987) Survey paper-a review of empty flows and fleet management models in freight transportation. Transp Sci 21(4):227-248

Ding S (2015) The \$lalpha \$-maximum flow model with uncertain capacities. Appl Math Model 39:2056-2063 
Ding S (2017) Uncertain minimum cost multicommodity flow problem. Soft Comput 21(1):223-231

Ding S, Gao Y (2014) The (\$sigma \$, s) policy for uncertain multiproduct newsboy problem. Expert Syst Appl 41:3769-3776

Ding S, Zeng XJ (2018) Uncertain random assignment problem. Appl Math Model 56:96-104

Epstein R, Neely A, Weintraub A, Valenzuela F, Hurtado S, Gonzalez G, Beiza A, Naveas M, Infante F, Alarcon F et al (2012) A strategic empty container logistics optimization in a major shipping company. Interfaces 42(1):5-16

Erera A, Savelsbergh MMJ (2009) Robust optimization for empty repositioning problems. Oper Res 57(2):468-483

Erera AL, Morales JC, Savelsbergh M (2005) Global intermodal tank container management for the chemical industry. Transp Res Part E Logist Transp Rev 41(6):551-566

Finke S (2017) Empty container repositioning from a theoretical point of view. In: Dynamics in logistics. Springer, pp 325-334

Florez H (1986) Empty-container repositioning and leasing: an optimization model. In: Mikrofiche-Ausg, Brooklyn, Polytechnic University, PhD Thesis. University Microfilms International, Ann Arbor

Gao Y (2011) Shortest path problem with uncertain arc lengths. Comput Math Appl 62(6):2591-2600

Gao Y (2012) Uncertain inference control for balancing an inverted pendulum. Fuzzy Optim Decis Mak 11(4):481-492

Gao X, Gao Y (2013) Connectedness index of uncertain graphs. Int J Uncertain Fuzziness Knowl Based Syst 21(1):127-137

Gao Y, Yang L, Li S (2016) Uncertain models on railway transportation planning problem. Appl Math Model 40(7):4921-4934

Gen M, Syarif A (2005) Hybrid genetic algorithm for multi-time period production/distribution planning. Comput Ind Eng 48(4):799-809

Hafezalkotob A, Zamani S (2018) A multi-product green supply chain under government supervision with price and demand uncertainty. J Ind Eng Int 1-14

Hamidi M, Shahanaghi K, Jabbarzadeh A, Jahani E, Pousti Z (2017) Determining production level under uncertainty using fuzzy simulation and bootstrap technique, a case study. J Ind Eng Int 13(4):487-497

Hosseini S (2013) A model-based approach and analysis for multiperiod networks. J Optim Theory Appl 157(2):486-512

Hosseini S (2015) Time-dependent optimization of a multi-item uncertain supply chain network: a hybrid approximation algorithm. Discrete Optim 18:150-167

Hosseini S, Wadbro E (2016) Connectivity reliability in uncertain networks with stability analysis. Expert Syst Appl 57:337-344

Hosseini S, Sahin G, Unluyurt T (2014) A decomposition-based approach for the multiperiod multiproduct distribution planning problem. J Appl Math 201:Article ID 825,058, 25 pp

Ji Y, Yang H, Zhu Q, Xing Y (2016) Optimization model of empty container reposition of liner alliance based on mutually renting strategy in short sea service. In: Proceedings of the 6th international Asia conference on industrial engineering and management innovation. Springer, pp 1055-1064

Lai M (2013) Models and algorithms for the empty container repositioning and its integration with routing problems. $\mathrm{PhD}$ thesis, Universita'degli Studi di Cagliari

Lam SW, Lee LH, Tang LC (2007) An approximate dynamic programming approach for the empty container allocation problem. Transp Res Part C Emerg Technol 15(4):265-277

Langroodi R, Amiri M (2016) A system dynamics modeling approach for multi-level, multi-product, multi-region supply chain under demand uncertainty. Expert Syst Appl 51:231-244

Lee CY, Meng Q (2014) Handbook of ocean container transport logistics: making global supply chains effective, vol 220. Springer, Berlin
Liu B (2007) Uncertainty theory. In: Uncertainty theory. Springer, pp 205-234

Liu B (2010a) Uncertainty theory: a branch of mathematics for modeling human uncertainty. Springer, Berlin

Liu W (2010b) Uncertain programming models for shortest path problem with uncertain arc lengths. In: Proceedings of the first international conference on uncertainty theory, Urumchi, China, pp $148-153$

Liu B (2012) Why is there a need for uncertainty theory. J Uncertain Syst 6(1):3-10

Long Y, Lee LH, Chew EP (2012) The sample average approximation method for empty container repositioning with uncertainties. Eur J Oper Res 222(1):65-75

Long Y, Chew EP, Lee LH (2015) Sample average approximation under non-iid sampling for stochastic empty container repositioning problem. OR Spectr 37(2):389-405

Memon M, Lee Y, Mari S (2015) Group multi-criteria supplier selection using combined grey systems theory and uncertainty theory. Expert Syst Appl 42:7951-7959

Moghaddam K (2015) Fuzzy multi-objective model for supplier selection and order allocation in reverse logistics systems under supply and demand uncertainty. Expert Syst Appl 42:6237-6254

Newman A, Yano C (2000) Scheduling direct and indirect trains and containers in an intermodal setting. Transp Sci 34(3):256-270

Nourifar R, Mahdavi I, Mahdavi-Amiri N, Paydar MM (2018) Optimizing decentralized production-distribution planning problem in a multi-period supply chain network under uncertainty. J Ind Eng Int 14(2):367-382

Olivo A, Zuddas P, Di Francesco M, Manca A (2005) An operational model for empty container management. Marit Econ Logist 7(3):199-222

Poo MC-P, Yip TL (2017) An optimization model for container inventory management. Ann Oper Res 1-21

Rashidi H, Tsang E (2015) Vehicle scheduling in port automation: advanced algorithms for minimum cost flow problems. CRC Press, Boca Raton

Rodrigue J, Notteboom T (2015) International trade and freight distribution. In: Southwest transportation workforce center Connecting and empowering the transportation workforce. California State University, Long Beach

Shen W, Khoong C (1995) A DSS for empty container distribution planning. Decis Support Syst 15(1):75-82

Shintani K, Konings R, Imai A (2010) The impact of foldable containers on container fleet management costs in hinterland transport. Transp Res Part E Logist Transp Rev 46(5):750-763

Shishebori D, Babadi AY (2018) Designing a capacitated multiconfiguration logistics network under disturbances and parameter uncertainty: a real-world case of a drug supply chain. J Ind Eng Int 14(1):65-85

Song DP, Carter J (2009) Empty container repositioning in liner shipping 1. Marit Policy Manag 36(4):291-307

Song DP, Dong JX (2015) Empty container repositioning. In: Handbook of ocean container transport logistics. Springer, pp 163-208

Song D, Zhang Q (2010) A fluid flow model for empty container repositioning policy with a single port and stochastic demand. SIAM J Control Optim 48(5):3623-3642

SteadieSeifi M, Dellaert N, Nuijten W, Van Woensel T, Raoufi R (2014) Multimodal freight transportation planning: a literature review. Eur J Oper Res 233(1):1-15

Tofighian AA, Moezzi H, Barfuei MK, Shafiee M (2018) Multiperiod project portfolio selection under risk considerations and stochastic income. J Ind Eng Int 1-14

Ünlüyurt T, Aydın C (2012) Improved rehandling strategies for the container retrieval process. J Adv Transp 46(4):378-393 
Vis IF, Roodbergen KJ (2009) Scheduling of container storage and retrieval. Oper Res 57(2):456-467

Wang H, Tanaka K (2016) Management of empty container repositioning considering leveling marine container logistics. In: Techno-Ocean (Techno-Ocean). IEEE, pp 682-686

Wang J, Zhu J, Yang H (2013) Reliable path selection problem in uncertain traffic network after natural disaster. Mathematical Problems in Engineering pp Article ID 413,034, 5 pp

Wang Z, Guo J, Zheng M, Yang Y (2015) A new approach for uncertain multi objective programming problem based on \$ $\backslash$ mathscr $\{\mathrm{P}\}\}_{-} \backslash$ mathtt $\{\mathrm{e}\} \$$ principle. J Ind Manag Optim 11(1):13-26

Wong EY, Tai AH, Raman M (2015) A maritime container repositioning yield-based optimization model with uncertain upsurge demand. Transp Res Part E Logist Transp Rev $82: 147-161$
Yao K, Liu B (2017) Uncertain regression analysis: an approach for imprecise observations. Soft Comput 1-4

Yi S, Scholz-Reiter B, Kim KH (2016) Collaborative carry-out process for empty containers between truck companies and a port terminal. In: Dynamics in logistics. Springer, pp 473-482

Zhang B, Peng J (2013) Uncertain programming model for uncertain optimal assignment problem. Appl Math Model 37(9):6458-6468

Zhang B, Ng C, Cheng T (2014) Multi-period empty container repositioning with stochastic demand and lost sales. J Oper Res Soc 65(2):302-319

Zhang H, Lu L, Wang X (2017) Two stages empty containers repositioning of Asia-Europe shipping routes under revenue maximization. In: International Conference on Intelligence Science. Springer, pp 379-389 